Moreno-Veloza, L.E. y Garzón-Martínez, M.A. (2019). Del infierno al cielo en Boyacá: valoración patrimonial de un camino. Revista de Antropología y Sociología: VIRAJES, 21(2), 133-155. DOI: 10.17151/rasv.2019.21.2.7

\title{
Del infierno al cielo en Boyacá: valoración patrimonial de un camino
}

\author{
LYDA ESPERANZA MORENO-VELOZA* \\ MARÍA ANGÉLICA GARZÓN-MARTÍNEZ**
}

Recibido: 2 de febrero de 2019

Aprobado: 29 de abril de 2019

Artículo de investigación

\footnotetext{
* Lyda Esperanza Moreno Veloza es Especialista en Gerencia de Pequeñas y Medianas Empresas, Administradora Turística y Hotelera. Docente Universitaria. Pertenece al Grupo Interdisciplinario de Investigaciones Arqueológicas e Históricas GIIAH de la UPTC. Universidad Pedagógica y Tecnológica de Colombia. Tunja, Boyacá, Colombia. E-mail: lydaemv@gmail.com. • ORCID: 0000-0001-5151-531X Google Scholar

** María Angélica Garzón Martínez es Doctora en Ciencias Humanas y Sociales. Docente de la Maestría en Patrimonio Cultural de la Universidad Pedagógica y Tecnológica de Colombia. Pertenece al Grupo Interdisciplinario de Investigaciones Arqueológicas e Históricas GIIAH de la UPTC. Universidad Pedagógica y Tecnológica de Colombia. Tunja, Boyacá, Colombia. E-mail: maria.garzon03@uptc.edu.co (1) ORCID: 0000-0003-1753-1476. Google Scholar
} 


\title{
Resumen
}

El artículo analiza parte del camino prehispánico entre el infierno y el cielo que conecta el municipio de Turmequé con Ventaquemada en el departamento de Boyacá. Se explora su trayecto desde una perspectiva patrimonial que permite indagar por valores naturales, arquitectónicos, culturales y arqueológicos. Metodológicamente, se hace un acercamiento etnográfico en el que se resaltan las vivencias, testimonios y recuerdos de las personas que habitan el camino. Así mismo, sus prácticas tradicionales, saberes y usos. Mediante la categoría de itinerario cultural se proponen valoraciones a propósito del ambiente natural que lo rodea, la arquitectura de piedra que lo caracteriza y los testimonios de pasados prehispánicos, coloniales y modernos que aún conserva. Se concluye resaltando la necesidad de elaborar una estrategia para que la comunidad apropie el camino entendiendo el itinerario cultural no como un fin sino como un medio para salvaguardarlo en un contexto que parece condenarlo al olvido.

Palabras clave: caminos, patrimonio cultural, itinerario cultural, Boyacá, arquitectura, peregrinaje.

\section{From Hell to Heaven in Boyacá: Heritage Assessment of a Road}

\begin{abstract}
The article analyzes part of the pre-Hispanic road between hell and heaven that connects the Municipality of Turmequé with Ventaquemada in the Department of Boyacá. Its path is explored from a heritage perspective which allows inquiring about natural, architectural, cultural and archaeological values. Methodologically, an ethnographic approach is made in which the experiences, testimonies and memories of the people who inhabit the road are highlighted as well as their traditional practices, knowledge and uses. Through the category of cultural itinerary, valuations are proposed regarding the natural environment that surrounds it, the stone architecture that characterizes it and the testimonies of pre-Hispanic, colonial and modern pasts that it still retains. The article concludes by highlighting the need to develop a strategy for the community to appropriate the path by understanding the cultural itinerary not as an end but as a means to safeguard it in a context that seems to condemn it to oblivion.
\end{abstract}

Key words: roads, cultural heritage, cultural itinerary, Boyacá, architecture, pilgrimage. 


\section{Introducción}

El ritmo del camino favorecía que las sendas no fueran sólo lugares de paso, sino que suponían espacios de vida, lugares ahora llenos de memoria callada. Emilio Molero López-Barajas (2013)

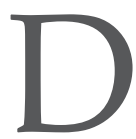
espués de varias horas de recorrido sorteando las dificultades que la cuesta impone las personas anuncian: ¡Vamos llegando al cielo! Este es el final del camino y, como popularmente se dicen en la región, la "coronación" de la montaña. Ubicado en la provincia de Márquez en el departamento de Boyacá (Colombia), a una distancia de 45 kilómetros de Tunja y 133 kilómetros de Bogotá, el camino inicia en el municipio de Turmequé y finaliza en Ventaquemada después de recorrer 10,6 kilómetros de trayecto. Atravesando parte de las provincias de Márquez y Centro, el camino conecta las veredas de Rosales y Rinchoque de Turmequé con Sota, Nerita, Puente de Piedra y Supatá de Ventaquemada.

De origen prehispánico, con trazos angostos y de difícil tránsito, el camino fue construido para dar paso a personas y animales de carga con fines de poblamiento e intercambio económico (Peñuñuri, 2016). Hoy el camino sigue siendo un referente para la población que lo habita y lo transita, un lugar inscrito de memorias y de riquezas ambientales, arqueológicas y culturales. A pesar de la introducción de carreteras, nuevas formas arquitectónicas, modelos económicos y usos para el camino, su función como eje de encuentro y articulación de la población sigue estando vigente.

Ejemplo de lo anterior son las actividades y significados que frente a lo religioso el camino propicia. Escenario de diversas peregrinaciones religiosas como la conmemoración a la Santa Cruz, a la Virgen del Carmen, San Isidro o el Señor de los Milagros, el camino permite aquello que Martorell (2003) denomina flujo de elementos espirituales:

los idiomas; la fe y las creencias religiosas; los sistemas de relación humana; la música, la danza y el canto; los sistemas administrativos y políticos; los criterios artísticos; los métodos de construcción; los usos y las costumbres culinarios y otros saberes. (p. 20)

La fuerte asociación entre la religión católica y la práctica del camino permite entender porque en la región se le conoce como "entre el infierno y el cielo" forma en que lo llaman sus transeúntes y pobladores. 
En sociedades poco mecanizadas, de carácter rural y de zonas montañosas, la práctica del caminar para transportarse de un lugar a otro sigue siendo común a diferencia de sociedades urbanizadas donde dicha práctica comienza a asociarse con el tiempo de ocio, el turismo o el deporte (Molero, 2013). En sociedades rurales, las redes de caminos que conectan al territorio continúan siendo utilizadas de manera frecuente a pesar del desarrollo de carreteras. Los caminos, independiente a su progresivo abandono, articulan relaciones sociales, prácticas y significados; son, en síntesis, un "cúmulo de experiencias y vivencias" (Molero, 2013, p. 52) que dan sentido a trayectos cotidianos.

Por ello, no resulta extraño que el nombre del camino explorado desborde la denominación religiosa "infierno-cielo" para referir una serie de experiencias, geografías y valoraciones relacionadas con su práctica: transitar del infierno al cielo. El infierno hace referencia a la parte más baja del recorrido donde el calor, algunas veces, se torna insoportable. Por su parte, el cielo es la parte más alta donde la montaña finaliza. El trayecto implica la dificultad de ascender piedra a piedra mirando hacia arriba hasta llegar a la planicie. El sacrificio, la constancia y el cielo como meta, son elementos que significan la práctica de este camino. Igualmente, la compañía en su trayecto de personajes, historias y lugares que lo convierten en testigo de una historia colonial pasada y de un presente de retos que implica la rápida transformación del mundo rural.

Desde el campo del patrimonio cultural el interés por los caminos, rutas e itinerarios resulta central hoy en día. Hernández (2011) explica que dicho interés está mediado por la crisis del medio ambiente, la búsqueda de cierta autenticidad de las culturas, la expansión del patrimonio y el mercado del turismo que apunta cada vez más a espacios naturales y sociedades particulares. Por su parte, Arcila, López y Fernández (2015) comentan que las dinámicas que promueven las valoraciones de estos recorridos y puntos de contacto como bienes patrimoniales deviene de la necesidad de recrear cierta conciencia identitaria, pero particularmente, de implementar un desarrollo basado en los recursos territoriales. Los anteriores autores coinciden en señalar que este interés se enmarca en dinámicas propuestas desde el llamado turismo cultural (Soro y González, 2015).

Una perspectiva diferente es la ensayada por Botero (2007) quien señala que los caminos son símbolos de avance cultural, de civilización y de la transformación de la naturaleza a manos del ser humano. Son testigos privilegiados de la historia, el desarrollo territorial y el avance en técnicas y procesos de construcción. Pero también, pueden ser muestra de decadencia y abandono cuando pierden sus funciones, son modificados drásticamente o caen en el olvido. El presente artículo se enmarca en esta perspectiva. 
Entiende que el camino "entre el infierno y el cielo" es un bien comunitario y cultural que vale la pena visibilizar y apropiar pues es memoria viva de la región. Así, el objetivo del artículo es el de exponer algunos elementos relacionados a prácticas y significados del camino con el fin de proponer parámetros para su reconocimiento y conservación. Su perspectiva de análisis se aleja del marketing territorial o la promoción de lugares desde una perspectiva turística en el escenario planetario (Hernández, 2011) para centrarse en la idea del camino como catalizador de memorias, experiencia y vinculaciones con el lugar (Molero, 2013).

El artículo se deriva de la investigación titulada “Entre el infierno y el cielo hay un camino en Boyacá: pasos para la interpretación", desarrollada en el marco de la Maestría en Patrimonio Cultural de la Universidad Pedagógica y Tecnológica de Colombia. Esta investigación acudió a una mirada etnográfica que incluyó trabajos de exploración del camino, su levantamiento cartográfico, recorridos, entrevistas y charlas con sus habitantes. De la metodología propuesta por Ferro (2009), para el estudio de los caminos se retomaron las guías de observación y valoración cultural que invitan a:

Observar lo cotidiano, aprender a estar, aprender a leer los códigos y los signos-símbolos con que las culturas instauran y ordenan el mundo (...) aprendiendo a viajar física y espiritualmente para encontrarse con el otro, un viaje que debe activar nuestra mente y nuestros sentidos al encuentro de nuestra identidad en un diálogo de espejos que ofrece la alteridad. (p. 1)

Para una caracterización más específica, se tomaron como referentes algunos de los datos utilizados para la evaluación del Camino de la Gran Ruta Inca o Qhapaq Nan como, por ejemplo: trazado del camino, emplazamiento, técnica constructiva, material de construcción, tipo de camino, técnica constructiva del muro, factores de deterioro, estado de conservación, procesos y efectos de deterioro, uso actual del camino. También se realizó el levantamiento topográfico del tramo y su altimetría.

Por último, se elaboró una ficha arqueológica que permitió el levantamiento de la información de la pintura rupestre ubicada a orillas del camino, ubicación, descripción, morfología, conservación y registro fotográfico desde diferentes visuales. Todo el trabajo de reconocimiento, descripción y valoración del camino se hizo de la mano de sus habitantes, visitantes y expertos en disciplinas como arquitectura, antropología, biología y administración turística y hotelera. 
Para el cumplimiento de su objetivo, el artículo se divide en tres partes. La primera, denominada "Ascender del infierno al cielo" presenta el camino mediante un recorrido por uno de sus trayectos, el encuentro con personas, objetos y vivencias que dan cuenta de la singularidad y riqueza del mismo. El segundo apartado, "El camino: elementos para valorarlo y amenazas que enfrenta", expone los valores patrimoniales encontrados en el camino y las amenazas que ponen en riesgo su permanencia en el territorio. La tercera parte, "Itinerario cultural: transitar del medio al fin", elabora las posibilidades de gestión del camino a partir de la categoría de itinerario cultural ya no como el fin de la valoración patrimonial sino como un medio de apropiación y sostenibilidad.

\section{Ascender del infierno al cielo}

El punto inicial del camino se ubica en la actual plaza de mercado de ganado de Turmequé que funciona desde hace muchos años todos los lunes a dos cuadras del costado occidental del parque principal. Es una de las plazas de ganado más populares de la región por su importante comercialización de vacas, cerdos, ovejas y caballos. De allí se toma vía al "infierno" por un lugar conocido como el "Valle de las Trompetas" donde se une el río Muincha y el río Ventaquemada. Aquí es posible encontrar los primeros vestigios de la época prehispánica representados en pinturas rupestres inscritas en las "Piedras muiscas", llamadas así por sus habitantes y ubicadas en la vereda Rinchoque jurisdicción de Turmequé.

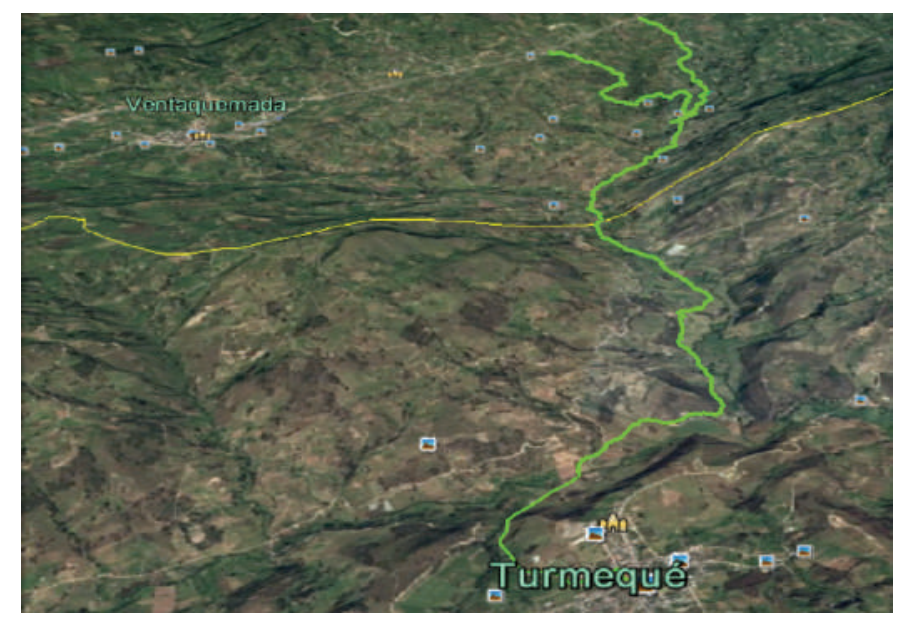

Imagen 1. Panorámica del camino ubicado en los municipios de Turmequé y Ventaquemada, indicado por la línea verde. División intermunicipal línea amarilla. Fuente: IGAC-Sistema Referencia MAGNA-SIRGAS. 
Los pobladores del camino han elaborado toda una serie de historias respecto a estas pinturas, sus orígenes y lo que representan hoy en día. Doña Chiquinquirá, habitante de la vereda de Nerita y tal vez la persona más longeva del camino comenta: "los indios sachichas vivían aquí a la orilla del río y guardaban debajo de estas piedras sus tesoros, todavía hay días que vienen y cantan, en esas piedras de hoyuelos batían la chicha". Otros pobladores otorgan características mágicas a este lugar al considerarlo hogar de los espíritus de sus ancestros. Alrededor de estas piedras y otros lugares del camino se han tejido leyendas, relatos y topónimos alusivos al personaje del diablo, indicador de la forma como en la memoria colectiva boyacense reposan fuertes referencias a la conquista de este territorio y la guerra de imágenes desatada en él para poseerlo (Gruzinski, 1994).

La llegada al "infierno" es anunciada por el olor dulce que lo rodea. El calor de esta tierra beneficia la producción de frutales como el durazno, la manzana, la pera, la curuba o la naranja. En el pasado, esta zona se caracterizó por la alta producción frutal. Doña Chiquinquirá rememora imágenes de árboles "cargados" y tejados de casas invadidos por los duraznos y las manzanas. Siguiendo el camino y aproximadamente a dos kilómetros de distancia se llega a la falda de la peña del diablo donde inicia el ascenso y comienzan a mostrarse los primeros muros de tapia pisada; una técnica antigua de construcción utilizada por poblaciones rurales que consiste en compactar tierra en un encofrado formando muros de entre los 40 y 60 centímetros de ancho logrando aislamiento y óptimas condiciones térmicas y acústicas (De La Peña, 1997).
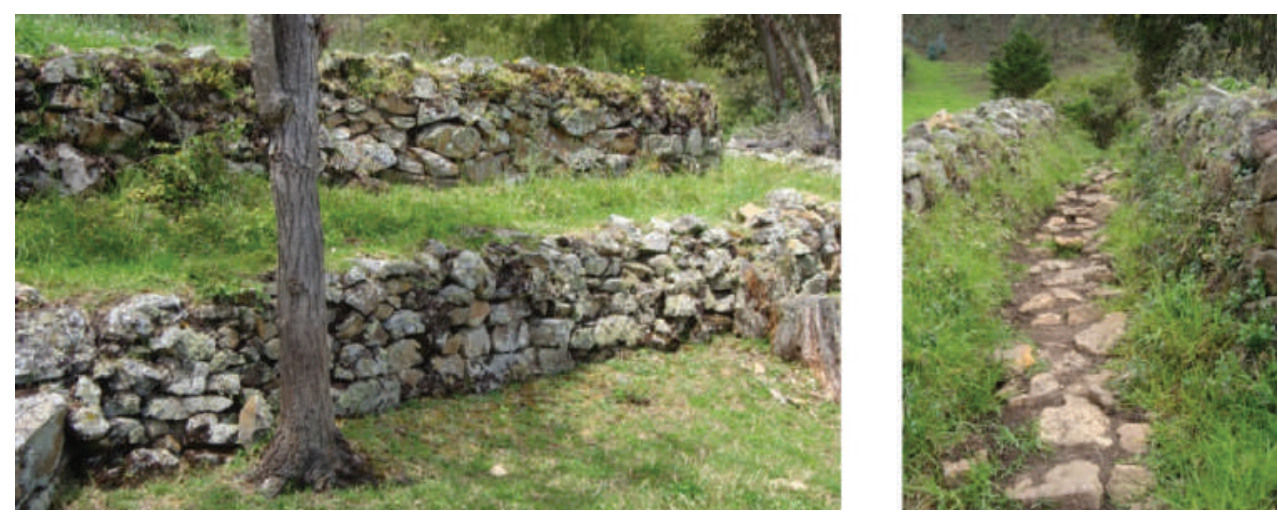

Imagen 2. Muro de contención en piedra al lado y lado del camino y la calzada. Fuente: Moreno (2015). 
Nos acercamos a la hacienda La Magdalena: “antiguo monasterio de padres Dominicos del siglo XVII de propiedad actual de los herederos de José Mora Rubiano y Lucía Calderón Rodríguez" explica María Elisa Mora, actual propietaria. La Magdalena es una casa colonial con espacios cerrados que giran en torno a un patio central, muros de gran grosor, ventanas y puertas en madera color negro, una capilla en la cual se presidían celebraciones religiosas y el espacio donde funcionaron las caballerizas; es muestra del resplandor político y económico de familias prestigiosas que habitaron el camino. Según Eufrasio Bernal (2008):

Desde el siglo XVIII operaba en el municipio una célula de "librepensadores" vinculada a Antonio Nariño que, aunque perdió fuerza con las muertes y desplazamientos de la década del cincuenta, dejó su legado bajo tierra. Los miembros se reunían en la hacienda La Magdalena a las afueras de Turmequé. (p. 189)

En la actualidad la hacienda La Magdalena es administrada por María Elisa quien regresó de la ciudad después de mucho tiempo para dedicarse a cultivar la tierra: "me encanta el contacto con la gente la naturaleza, la buena cocina y la fabricación de alimentos con los productos que se producen en nuestro hogar; adoro compartir y transmitir mis conocimientos y experiencias con quienes vienen a visitar este espacio". María Elisa aprovecha el espacio físico, natural y de producción que brinda la hacienda para promocionar experiencias turísticas asociadas a la permacultura o la relación armónica entre producción agrícola y sistemas sociales, políticos y económicos.

Siguiendo el camino y cerca de La Magdalena se encuentran dos haciendas de características similares: la hacienda Aposentos y la hacienda Baza. La primera ubicada en la orilla de la vía que comunica a Turmequé con Nuevo Colón y Úmbita y la segunda a tres kilómetros del centro de Tibaná. De la hacienda Aposentos se sabe que sus actuales dueños son doña Beatriz Azuero de Muñoz y los herederos que aún la conservan. Por su parte, la hacienda Baza resulta más reconocida en el territorio por ser un convento de los padres Dominicos dedicado a la evangelización de los indígenas de la región que data del siglo XVII. Hoy y después de un gran trabajo de restauración, la hacienda se ha convertido en uno de los establecimientos de alojamiento de mayor importancia de la región. 
Posterior a las haciendas se encuentra la casa de doña Chiquinquirá, punto donde el camino se divide en dos tramos: uno se dirige a la vereda de Puente de Piedra y el otro, a la vereda de Supatá. Decidimos ir por el trayecto de Puente de Piedra pues allí es posible observar la riqueza pétrea del camino. Las piedras tienen un referente social y cultural de importancia. En el pasado fueron usadas como lavaderos comunitarios donde las mujeres vecinas al río fregaban ropa, se bañaban e intercambiaban conocimientos. Era un escenario que provocaba el encuentro y la construcción de redes de apoyo. Como referente social, las rocas funcionan como hitos que permiten recordar la forma en que en épocas de lluvia los ríos se volvían caudalosos posibilitando el funcionamiento de las tradicionales acequias, acueductos artesanales que conducen agua para el consumo humano y su uso en los cultivos. Actualmente, los caudales han disminuido notablemente a causa de las transformaciones que viene sufriendo la capa vegetal.

En el recorrido, a lo largo del río Nerita, es posible encontrar piedras de diversos tamaños y formas. Algunas se destacan por las moyas que se han venido formando de manera natural. Las moyas suelen ser profundas o superficiales, amplias, multiformes, resaltándose la forma circular casi perfecta que el agua ha hecho en ellas. Los habitantes del camino han asignado nombres y relatos a cada roca. Según la tradición oral, encontramos "la moya de la fertilidad", "la moya de la chicha", "la moya de consagración de los niños a la tierra y del culto a las semillas". Algunas de estas moyas se usaron para servir la chicha en los recorridos, otras cobijaron a recién nacidos mientras sus mamás "veían" los animales, otras guardaban las monedas y objetos de oro de los indígenas que se desplazaban por aquel lugar y otras son asociadas con espantos que protegen los lugares sagrados.

Dentro de esta variedad, se encuentra la "piedra de los dibujos" denominada así por don Sacramento, otro poblador del camino. Esta piedra está pintada en tono ocre con trazos simétricos en forma de rombos que se orientan hacia la cara del río. Son la huella material de los indígenas que transitaron por este camino y que se niegan a desaparecer de él, puesto que, a pesar de estar expuesta a condiciones climáticas como la erosión, radiación solar, lluvia, humedad, crecimiento de líquenes, hongos y al depósito de minerales en la superficie de la roca; ha logrado permanecer. 


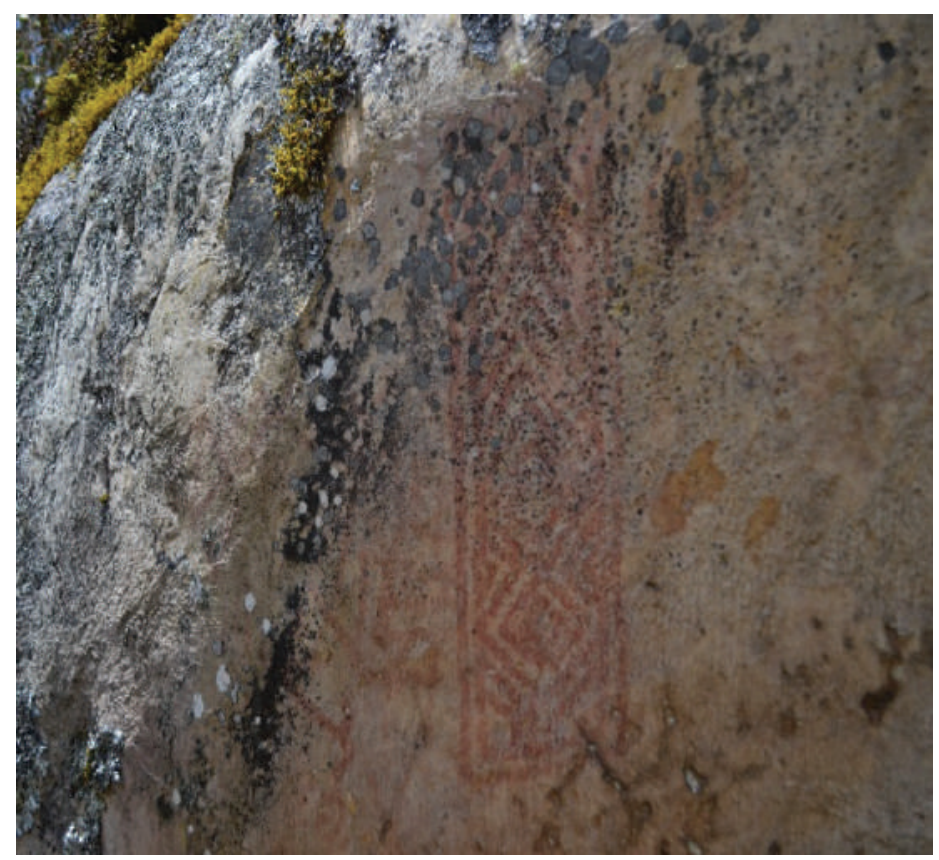

Imagen 3. Pintura Rupestre en la "Piedra Pintada". Fuente: Moreno (2015).

Al seguir para el cielo, nos encontramos con la primera escuela de Ventaquemada construida en 1930. Allí aún están en pie los dos salones en adobe donde recibían clase mujeres y hombres por separado. Don José de la Cruz, habitante de este tramo del camino, cuenta con gran entusiasmo:

Se cree que la escuela de Puente de Piedra fue fundada por ahí hacia 1910 más o menos, no hay una precisión, funcionaba en casas de familia, llamaban casas de familia los ranchitos hasta que hacia el año de 1930 o 1932, me parece construyeron el primer saloncito, el salón viejito en la casa que se está cayendo. Era un epicentro de la región porque venían a estudiar del centro, de Nerita, de Supatá, de Montoya, porque Montoya no tenía escuela, toda la región venía acá.

Entonces, el camino, en tanto progreso, también puede dar fe de los procesos de alfabetización que comenzaron a extenderse en Colombia a inicios del siglo XX.

Otra característica del camino es la evidencia de la explotación de cal. En varios de sus tramos las laderas de la montaña presentan perforaciones donde existían dichas minas. La cal era explotada para utilizarla como abono de cultivos o como material de construcción. Al respecto, nos relata don 
Sacramento Porras: “Por ese camino sacaban cal de los hornos que había en Supatá, don Manuel Porras y Mariano Vela, lo sacaban en mulas. Pero ellos ya murieron". Por su parte, la profesora Susana Moreno recuerda: "era lo que daba trabajo aquí a todos los hombres, eso trabajaban de noche y de día, uno mandaba a los niños que le regalaran para abonar las matas y les daban por piedras, aquí se echaban en agua y listo". Así mismo, existen las minas de fosfórica, ubicadas en la vereda de Rosales que eran explotadas de manera rudimentaria de donde se extraían uno de los componentes del abono químico para la siembra de la papa. Siguiendo a don Abraham, habitante del camino: “Eso ya es Turmequé, yo no trabajé, pero allá trabajó mucha gente. Allá duraron como unos diez años sacando fosfórica, eso se terminó. Ahora sacan es el recebo para las carreteras. Eso se terminó como en el 75 y ahora quedó una recebera"1.

Las prácticas productivas tradicionales han dejado huella en el camino. De ello son muestra las huertas caseras que aún se mantienen. Pequeñas parcelas donde es posible coger todas las mañanas las hojas de col para dar sabor a las sopas, las habas, la matica de cebolla larga, arracacha, fríjol, calabazas, las hojas de risgua.

A su lado nace el cultivo de hierbas aromáticas y medicinales de las cuales hace uso la comunidad y vende o regala a los vecinos para aliviar las dolencias del cuerpo o prevención de enfermedades. Otras especies artesanales como el chusque o bambú andino siguen siendo utilizadas en la elaboración de canastos, cunas, cercas, corrales, puertas y techos; la caña brava con usos similares al chusque, las hojas de risgua utilizadas para envolturas de tamales y envueltos $y$, los helechos, planta silvestre utilizada para envolver carne.

En el recorrido del camino encontramos casas elaboradas tanto en bahareque como en adobe, técnicas tradicionales de construcción. La primera consistente en el armado de una estructura entretejida de madera que se cimienta con piedras y puede ser rellenada con barro, paja u otros materiales. Esta técnica ha sido utilizada especialmente por poblaciones indígenas de América del sur, es previa al adobe y se sigue utilizando como respuesta a necesidades de vivienda de poblaciones vulnerables. Por su parte el adobe, material compuesto por la mezcla de arcilla, arena, tierra y paja moldeada y secada al sol, es una técnica difundida en Asia, norte de Africa, América del sur y el oeste de Europa que data del Neolítico (De La Peña, 1997). Constituye una arquitectura vernácula, de fácil

\footnotetext{
${ }^{1}$ Recebera o cantera es el término utilizado para nombrar a la explotación minera, ubicada a cielo abierto, en la que se obtienen rocas industriales, ornamentales o áridos, en este caso las ubicadas en Turmequé son para uso vial, es decir, para construcción y mantenimiento de carreteras y caminos.
} 
adaptación para la zona andina y cuyo principal problema, la humedad, ha sido resuelto por campesinos del sector utilizando una cimentación de piedra para la colocación de muros y paredes.

Las casas del camino pueden ser bien representadas por casas como la de doña Bárbara, una casa en adobe de paredes blancas y techo de barro. Con patio central, cocina, bebedero en piedra para las gallinas, una yunta de bueyes colgada y, en una esquina, la letrina; la casa de doña Bárbara resulta paradigmática de las estructuras habitacionales del camino. En ella llaman la atención las memorias que se inscriben en sus paredes a manera de afiches y calendarios; algunos recuerdan la publicidad de marcas de cerveza o gaseosa que ya no se consumen en la región como la Fanta o eslóganes como: "Por mi tierra, por mis amigos". El calendario es el tradicionalmente usado con la imagen del Divino Niño donde se encuentran anotaciones del tipo: "Día 31 encargó la vaca chica", "Mi hermano fue enterrado el 2 de marzo del 2001", "el día 16 de mayo dio cría la vaca de Silverio y de Oscar una ternera normanda".

Y así, de charla en charla, de recuerdo en recuerdo y de la vivencia de un paisaje rico en recursos, historias y relaciones de parentesco, compadrazgo y amistad, se llega al cielo; la cúspide de la montaña que marca el final del recorrido o su comienzo puesto que el camino es trayecto tanto de ida como de regreso. En el tramo uno el cielo se corresponde con la vereda de Puente de Piedra donde culmina el camino al encontrarse con la carretera central del norte. Por el tramo dos, el cielo puede ubicarse en la vereda de Supatá donde, de igual manera que el trayecto uno, el camino se encuentra con la central del norte. Ahora bien, es importante especificar que el camino es mucho más largo de lo aquí descrito y que el "cielo" no marca necesariamente su fin. En el tramo uno, el camino continúa hacia los municipios de Samacá y Ráquira llegando hasta Chiquinquirá. En el tramo dos, continua su recorrido por las estribaciones del páramo el Rabanal.

\section{El camino: elementos para valorarlo y amenazas que enfrenta}

El camino "entre el infierno y el cielo" es una estructura vigente que sigue siendo utilizado por campesinos, comerciantes y peregrinos; propicia encuentros, saludos, intercambios y conexiones. En este sentido, el camino es práctica del espacio, significado de lo colectivo y elemento articulador de relaciones de solidaridad, amistad y servicio mutuo. El camino presenta así una serie de características desde las cuales es posible hacer una valoración patrimonial. 


\section{Testigo de la historia}

El camino puede considerarse como un trazo estratégico de la región por el cual ha transcurrido buena parte de su historia desde épocas prehispánicas. Las pinturas rupestres, el manejo de pendientes mediante escaleras y, en general, una arquitectura pedestre (Botero, 2007) evidencian un pasado prehispánico de construcción y apropiación territorial mediante el camino. Independientemente de su longitud o función primaria, este camino es muestra de la fuerte continuidad histórica de la que habla Botero (2006) al referirse a las adaptaciones realizadas por los españoles a los caminos prehispánicos con el fin de "permitir el paso continuado de caballos y ganado y de cientos de hombres cargados con cosas voluminosas, pesadas y muy difíciles de transportar por caminos estrechos y de fuertes pendientes" (p. 271).

Las haciendas del camino son testimonio del proceso colonizador y evangelizador emprendido con la llegada española a tierras americanas. Con un crecimiento acelerado a partir del s. XVII a causa del debilitamiento de la encomienda, el crecimiento de la población, ciertos derechos de propiedad y la dificultad de conectar grandes territorios; las haciendas se tornaron en ejes a partir de los cuales comenzaron a girar economías, poblamientos y surgimiento de nuevas élites económicas (Kalmanovitz, 2008).

Así, el camino es testigo de procesos sociales previos a la Colonia hasta procesos más contemporáneos como la importante extensión de la red vial que comienza a desarrollarse en Latinoamérica y el Caribe a partir de la década del 50 del siglo XX como parte del proyecto modernizador de estas sociedades (Schiiessler, 1992) lleva a que caminos como este terminen convirtiéndose en caminos secundarios, de menor importancia e, inclusive, caminos olvidados. Entonces, el valor histórico del camino se cifra no en la posibilidad de ubicar su construcción en una época particular sino en el palimpsesto que representa.

\section{Camino de peregrinaje}

La idea de peregrinaje como un destierro permanente o como búsqueda constante de la "tierra prometida" es una idea que puede rastrearse desde el catolicismo medieval donde ya es posible detectar una conciencia del peregrino (Cardini, 1988) que asocia las pruebas de su peregrinaje - el cansancio, los peligros - al recorrido que debe hacer para llegar a orilla segura: el santuario, la santidad, el cielo. Entonces, el peregrino viaja porque el viaje es representación de su sacrificio. Viaja también, porque 
paga penitencias, necesita pedir un "favor" o, por el contrario, agradecer un beneficio recibido. Este tipo de peregrinaciones son comunes en el camino estudiado: grupos de cinco a veinte personas organizan el recorrido, preparan alimentos, bebidas, zapatos cómodos, alistan las peticiones, reflexionan sobre sus culpas e inician el recorrido.

La primera peregrinación que vive el camino es en enero hacia el santuario de Nuestra Señora del Amparo, protectora de los peligros, vía Chinavita. A esta peregrinación asisten personas de Ventaquemada, Turmequé, Nuevo Colón y pueblos aledaños. El dieciocho del mismo mes se realiza otra peregrinación, esta vez dirigida a la Virgen de la Antigua en el municipio de Nuevo Colón. En febrero, la peregrinación se dirige hacia el santuario de Nuestra Señora de la Candelaria en Ráquira. En Semana Santa, los peregrinos recorren el camino para dirigirse al santuario de Nuestra Señora de Chiquinquirá. Estas peregrinaciones tienen una característica en común: se dirigen hacia santuarios marianos puesto que la región en general profesa una fe importante hacia la figura de María, símbolo de santidad.

El peregrinaje es una de las actividades más importantes del camino y tal vez una de mayor significado para sus transeúntes y habitantes. Es una tradición de décadas que ha pasado de generación en generación y que tiene asociada toda una planeación familiar para poder realizarla. No es, de ninguna forma, un acontecimiento improvisado. La valoración religiosa del camino está dada por la importante actividad que este propicia, la conexión que permite entre diversos santuarios, la tradición de peregrinaje con que se asocia y, especialmente, porque le permite al peregrino transitar un camino que más que camino es, parafraseando a Cardini (1988), una metáfora de la vida.

\section{Arquitectura de tierra}

El uso del barro como material de construcción es un común denominador del camino. El adobe y la tapia pisada conforman una arquitectura de tierra (Guerrero, 2007), que ha sido utilizada tradicionalmente por pueblos indígenas de Suramérica y otras regiones del planeta según Muelle (como se citó Vargas, 2013). La arquitectura de tierra (Guerrero, 2007), se origina en necesidades locales que son sorteadas mediante los elementos que ofrece el medio transformándolos en materias primas o, para este caso, materiales de construcción. 

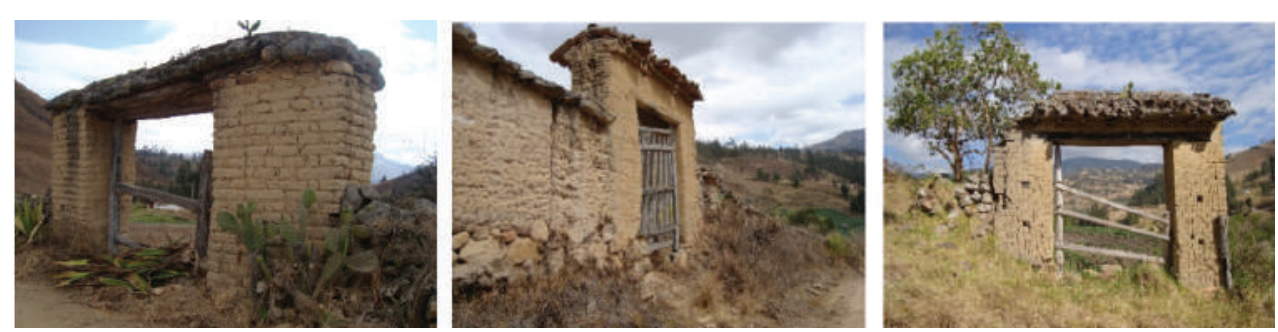

Imagen 4. Portales en adobe, tapia pisada al ingreso de algunas fincas. Fuente: Moreno (2015)

El adobe es un material resistente de construcción, protege del clima exterior y del sonido, es económico y para su procesamiento y estabilización no requiere de cocción o elementos químicos; solamente barro, agua y sol. Como bien lo señala Guerrero (2007), el adobe y la tapia pisada son parte de una tradición que se desarrolla a partir del saber tradicional y se transmite de generación en generación. Para este autor,

Las dimensiones de los elementos constructivos, sus formas de disposición, unión o ensamble, entre muchos otros factores, obedecen a una lógica en la que se han logrado optimizar los recursos disponibles, estableciendo límites de acción precisos que son conocidos y heredados entre los miembros de la comunidad que comparte la sabiduría regional. (Guerrero, 2007, p. 10)

En efecto, al revisar los testimonios recogidos durante la investigación, es fácil inferir la forma cómo los habitantes del camino han sabido trabajar el barro, optimizarlo y moldearlo de acuerdo con sus necesidades. Al respecto, don Sacramento Porras, comenta:

Yo mismo hice mi casita de adobe la de abajo la del pedregal, siempre la quise así y me puse hacer los ladrillos con barro de ahí mismo, ¡jaaaa!, y le mezclé piedra pequeña, pasto y un poco de paja de esa de que sobraba de la cebada, también el molde con unas tablas, eso para hacer esos ladrillos duré siempre unos días, para que secaran y que saliera el sol, porque el calor hace que rinda.

Entonces, el valor de la arquitectura de tierra está cifrado en su materialidad, sus mecanismos y en el saber tradicional que esta representa y que desde la práctica del construir es transmitido de generación en generación. 


\section{Los acompañantes del camino}

En el camino es posible encontrarse con un ambiente natural y unas prácticas sociales que por su constancia y presencia se convierten en acompañantes del camino. En primera instancia, puede nombrarse a los ríos que atraviesa y que parecieran buscarse constantemente con el camino: el río Muincha que nace en el páramo de Castillejo en límites con Turmequé, Úmbita y Villapinzón, recorre parte del valle y continúa hacia la Orinoquía; el río Turmequé que da paso al Nerita y Puente de Piedra, dependiendo de la vereda que vaya atravesando, desde el cual se desprenden afluentes como el río Ventaquemada, que a medida que avanza toma los nombres de la quebrada del Salitre y la Cañada de Bojirque.

Un segundo acompañante del camino es el "Rey Espinoso" o mata de fique que por su forma de roseta conformada por hojas radicales largas, triangulares, carnosas y jugosas, es conocida en esta región con ese nombre. Del fique se extrae de forma artesanal una fibra gruesa que se teje con diferentes usos: costales, empaques, suela de cotizas o alpargatas, redes, cuerdas, enjalmas y capoteras. El fique constituía para los habitantes del camino una actividad económica y una forma de suplir ciertas necesidades. Doña Bárbara Porras recuerda:

Mi oficio era solo sacar fique y hacer los lazos pa' vender. Nos daban diez centavos por un lazo a veces quince centavos, hacíamos lazos pa'1 ganado y pa' las ovejas; pa'1 ganado si era veintidós brazadas y para una oveja si eran siete brazadas. También hacía costales, hilábamos fique y hacíamos chiles ralitos; mis hermanos tenían telares donde hacían ruanas y cobijas y en los mismos telares urdían la cabuya y hacían los chiles, los chiles eran los costales ralos para echar la papa, eso era un larguerón porque se hilvana ese fique y como unos veinte costales salían, lo urdían en el telar, los cortaba, los hilvanaba y los cocía por las orillas y estuvo su costal.

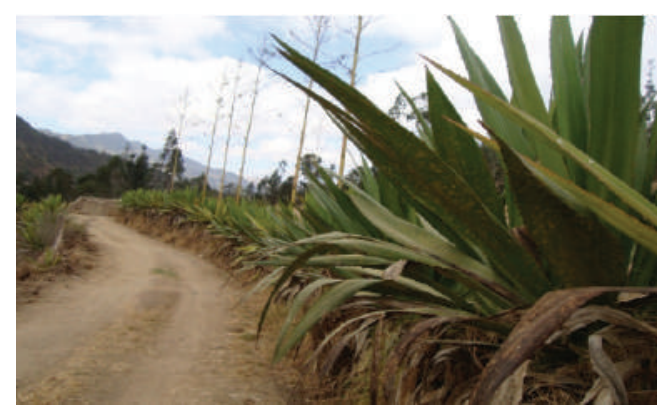

Imagen 5. Mata de fique que acompaña el camino. Fuente: Moreno (2015) 
La actividad económica derivada del fique comenzó a declinar cuando las hilanderías industriales de la región desplazaron los productos artesanales del mercado con productos elaborados en grandes cantidades $\mathrm{y}$, especialmente, la producción de los empaques de plástico que poco a poco fueron reemplazando a los costales elaborados con esta fibra. Hoy, la mata de fique reserva un lugar en el camino a manera de límite, como cerca natural utilizado en algunos predios con el fin de delimitarlos. Allí, silenciosamente ve pasar a campesinos y campesinas que en otros tiempos lo utilizaban, pero que ahora desconocen sus virtudes pues la tradición de hilarlo se ha perdido.

Contrario a lo sucedido con el fique, la medicina tradicional basada en plantas, aromas y bebidas que alivian cualquier "mal" sigue estando muy presente en los moradores del camino. Al igual que la agricultura de pancoger o de sobrevivencia que sigue alimentando a estas familias. Este sería el tercer acompañante del camino: la agricultura familiar. Alrededor del camino se mantiene vigente la tradición de la huerta casera en pequeñas parcelas. A su lado nace el cultivo de hierbas aromáticas y medicinales.

Respecto a los cultivos de pancoger, el camino ofrece en su recorrido uno de los tubérculos más importante de la zona andina: la papa amarilla, blanca y morada. Su siembra se produce a pequeña escala para el consumo doméstico, es uno de los cultivos más antiguos de la región y actualmente se le encuentra a lo largo de todo el camino y no solamente en su parte alta ("cielo"). Otros cultivos que acompañan el camino son los de fríjol, arracacha, hibias, cubios o nabos y chuguas.
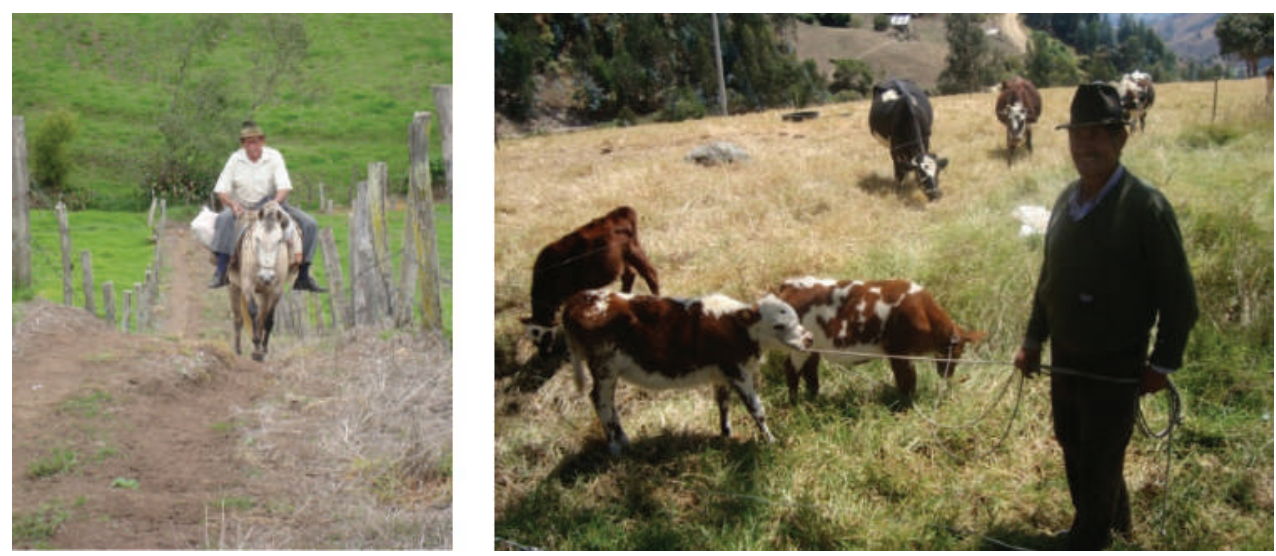

Imagen 6. Campesino a lomo de mula y actividad ganadera a la orilla del camino. Fuente: Moreno (2015). 
Finalmente, la ganadería como otra de las actividades productivas que se encuentran durante el recorrido del camino. Campanita, La Negra, La Pintada, La Cachuda, son algunos de los nombres que reciben las vacas que desde tempranas horas de la mañana son ubicadas en fila para ser ordeñarlas abasteciendo de esta forma a las familias habitantes del camino y a otras que se benefician con su producción. Campanita, La Negra, La Pintada y La Cachuda son también acompañantes del camino, ellas juntos a las mujeres que las atienden y desarrollan todas las labores que implica el "levante" bovino: ordeñar, remudar (colocar el corte de pasto), sacar la leche y entregarla al lechero.

\section{Un camino vivo/un camino en riesgo}

El camino "entre el infierno y el cielo" es muestra de los intercambios continuos y recíprocos de bienes, ideas, conocimientos, prácticas y valores que se propicia entre los pueblos que conforman la región central de Boyacá. Su recorrido, prácticas, estructura y arquitectura son el testimonio patrimonial del mismo. Piedras, pendientes, subidas, pinturas rupestres, arquitectura de tierra, camino de peregrinaje, casas, escuelas, ríos, vacas, hortalizas, medicina tradicional, tejido del fique, entre otras muchas cosas, nos hablan de un camino vivo que conserva sus funciones de tránsito y conexión agregando, para este caso particular, otras que tienen que ver con la cohesión social, el resguardo de prácticas tradicionales como la economía campesina y la solidaridad entre sus pobladores.

El camino ha sido un constructor de territorio que incorpora elementos de orden histórico, político-administrativo, económico, social y espacial a partir de dinámicas culturales y naturales que lo hacen susceptible de transformarse o de agotarse. Y es allí donde se encuentra la fortaleza del camino y su principal amenaza: en la capacidad de conservar su función social amoldándose a las nuevas exigencias del contexto. En efecto, el desarrollo, la economía neoliberal y el mercado global han modificado de forma importante redes de caminos mediante lógicas de modernización que han llevado al reemplazo de pequeños caminos por amplias y rápidas autopistas (Dalakoglou, 2010). Actualmente, las prácticas, tránsitos y aspectos culturales asociados al camino se encuentran en riesgo por: 
1. La migración importante de la población joven a zonas urbanas, principalmente, ciudades como Bogotá donde encuentran mayores oportunidades de estudio y laborales. Esto ha conllevado a que las actividades tradicionales como la agricultura, la ganadería y la construcción en barro dejen de realizarse por falta de mano de obra. La sabiduría tradicional que subyace a estas labores ha quedado reservada para los "viejos" a falta de una generación joven interesada en aprender y mantener tales prácticas.

2. La llamada "neo-ruralización” o migración al área rural de poblaciones urbanas que trasladan el estilo de vida urbano a las zonas campesinas cambiando su vocación y proponiendo exigencias en términos de condiciones de vida que no necesariamente se corresponden con las perspectivas de comunidades rurales.

3. La construcción de vías que han cruzado por el camino y lo han segmentado restándole valor patrimonial. La instalación de redes eléctricas y de gaseoductos también lo han afectado, modificando tanto su paisaje como los referentes sociales asociados al mismo.

4. La tala incontrolada por la acción del hombre, la potrerización, los cambios repentinos en los cultivos por "cultivos más productivos", el manejo de agroquímicos y fertilizantes de alto impacto ambiental ha producido cambios en la capa vegetal, pérdida de la diversidad y desequilibrio en el sistema ecológico.

El camino pareciera estar condenado a desaparecer debido a las dinámicas de cambio social y económico que han provocado su despoblamiento, aislamiento y el bajo ingreso económico de las familias que lo habitan. Por otro lado, el nuevo modelo de producción de la tierra por cultivos más productivos ha transformado el territorio, la estructura social de la comunidad, sus valores naturales y culturales. Es necesario, entonces, tomar acciones que permitan conservar el camino no como un ente estático que encapsula la cultura y la tradición sino como un mecanismo vivo que permite conservar aquello que las comunidades significan como valioso.

\section{Itinerario cultural: transitar del fin al medio}

El camino es testigo de cambios sociales, económicos y culturales que se han dado en la región y que han transformado su estructura, usos, formas, poblaciones y arquitecturas convirtiéndolo en un palimpsesto que evidencia cambios y continuidades entre los pasados prehispánicos, coloniales y modernos de los que ha hecho parte. En este sentido, el camino posee un valor intrínseco relacionado con su posibilidad de dar cuenta de 
estos pasados a través de sus piedras, pinturas, moyas, haciendas, tramos de carretera y otros que a manera de marcos sociales de la memoria encapsulan parte de este pasado, lo materializan y narran historias respecto a ellos.

Pero el camino no se agota en el aspecto histórico. Como ya ha sido demostrado, el camino posee una serie de valores de carácter patrimonial asociados al paisaje, la riqueza de recursos naturales, la arquitectura que lo caracteriza, sus lugares arqueológicos, cultura y prácticas asociativas. La denominación del camino como un recorrido entre el infierno y el cielo parte de unos referentes climáticos, religiosos y sociales que están vinculados a creencias, rituales y valores religiosos como a modos de vivir de sus habitantes reflejados en los espacios de viviendas, nombres, costumbres y prácticas cotidianas. De esta forma, el camino se manifiesta más allá de ser una vía de tránsito rural; es un espacio donde se despliegan una serie de prácticas económicas y de subsistencia que propician lazos sociales de afecto y solidaridad. Como lo señala Molero (2013) respecto a la cultura serrana: "un permanente deambular a pie o en caballerías, crearon un territorio de montaña que se estructuró sobre la existencia de espacios de relación, que en consecuencia generó un gran patrimonio caminero" (p. 57). En este sentido, el camino bien representa esquemas creativos y poéticos mediante los cuales las personas lo perciben y le asignan significados (Dalakoglou, 2010).

A pesar de lo anterior y de ser un camino que aún se encuentra vigente, las rápidas transformaciones del mundo rural propician una serie de amenazas que pueden sentenciarlo al desuso y, por lo tanto, al olvido. Por ello, es importante construir una alternativa que permita visibilizar su importancia mediante el reconocimiento no sólo de sus habitantes sino de las poblaciones que lo circundan, generando de esta forma su apropiación y conservación. Desde el patrimonio cultural son varias de las herramientas que pueden contribuir a esta tarea. Una de ellas, los itinerarios culturales.

Definido por El Comité Científico Internacional de Itinerarios Culturales como:

Toda vía de comunicación terrestre, acuática o de otro tipo, físicamente determinada y caracterizada por poseer su propia y específica dinámica y funcionalidad histórica al servicio de un fin concreto y determinado, que reúna las siguientes condiciones: Ser resultado y reflejo de movimientos interactivos de personas, así como de intercambios multidimensionales, continuos y recíprocos de bienes, ideas, conocimientos y valores entre pueblos, países, regiones o continentes, a lo largo de considerables períodos de tiempo. Haber generado una fecundación múltiple y recíproca, en el espacio y en el tiempo, de las culturas afectadas que se manifiesta tanto en su 
patrimonio tangible como intangible. Haber integrado en un sistema dinámico las relaciones históricas y los bienes culturales asociados a su existencia. (López y Vidargas, 2011, p. 11)

Los itinerarios culturales, entonces, se presentan como la dimensión más actual del patrimonio cultural porque permiten unir la importancia del patrimonio material e inmaterial y considerarlo en su totalidad (López y Vidargas, 2011). Los elementos intangibles del patrimonio son los que proporcionan significado a los itinerarios culturales, los cuales deben existir y ser reales, inscribirse en un contexto natural y estar apoyados en elementos tangibles. El camino, su arquitectura, conocimientos, prácticas y cultura permite considerarlo como un itinerario cultural, es decir, como una vía de comunicación concreta, históricamente determinable que ha propiciado encuentros, conexiones y movilidades que han tenido por efecto la interrelación entre las poblaciones que lo han recorrido y lo siguen utilizando.

La propuesta de gestión del camino desde la categoría de itinerario cultural no busca valorarlo para insertarlo en un mercado turístico sino reconocerlo para preservarlo. Aquí, el itinerario cultural es entendido no como el fin del proceso de reconocimiento patrimonial sino como un medio que permite adelantar dicho proceso. Así, no se pretende objetivar bienes culturales para convertirlos en productos turísticos (Hernández, 2011). Es más bien, una identificación de la dinámica que se presenta en este lugar y resaltar los aspectos del por qué el camino resulta valioso de acuerdo con los postulados de Pratts (1997), quien señala que el patrimonio es una construcción social en el que las comunidades son las llamadas a darle sentido y contenido reconociendo determinados lugares y objetos como necesarios de preservar.

En estos términos, el camino no es una simple vía histórica de comunicación que incluye o conecta diversos elementos patrimoniales, sino singulares fenómenos históricos. El camino sigue permitiendo el paso de agricultores, comerciantes, estudiantes, peregrinos, mineros, caminantes y visitantes, para algunos el camino hace parte de su vida, de su cotidianidad, la vía que lo lleva al trabajo, por donde van a su escuela, por allí transcurren motivaciones espirituales, paisajísticas o de simple gusto por caminar el camino.

Ahora bien, como lo señala Dalakoglou (2010), los caminos no son solamente construcciones sociales o narrativas, también son entidades físicas, espaciales y materiales. Los caminos contienen una dimensión material que desde los estudios antropológicos o sociológicos muchas veces se obvia restándole importancia. Formas de construcción, técnicas, tránsitos, 
recursos económicos y especialistas que intervienen en su construcción deben tenerse en cuenta tanto para la investigación de caminos como para su conservación (Dalakoglou, 2010; Harvey \& Knox, 2015).

El camino como itinerario cultural puede resultar en un espacio colectivo de transmisión y reconocimiento de la memoria, la historia y la cultura. A pesar de que las declaratorias no son siempre la solución para garantizar la protección y conservación de lugares significativos como este camino, pueden resultar en estrategia para diseñar, articular y poner en marcha una serie de acciones que convoquen a la comunidad, propicien la apropiación del camino, su cuidado, conservación y sostenibilidad en el tiempo.

Finalmente, vale la pena señalar que "virar" la mirada patrimonial hacia el estudio de este tipo de caminos permite romper el hábito de pensamiento que ha marcado el estudio de los caminos en el caso de América Latina que señala la importancia de los caminos reales asociados al proyecto de la conquista española frente a los caminos construidos por indígenas que suelen ser caracterizados como cortos y de menor importancia (Botero, 2007). El camino "entre el infierno y el cielo" es clara muestra de que los caminos en su singularidad son significativos y que a pesar de que nos lleven a transitar del infierno al cielo o del cielo al infierno, siempre valdrá la pena caminarlos.

\section{Referencias bibliográficas}

Arcila, M., López, J. y Fernández, A. (2015). Rutas turísticos-culturales e itinerarios culturales como productos turísticos: reflexiones sobre una metodología para su diseño y evaluación. En J. De la Riva, P. Ibarra y R.R. Montorio, Análisis espacial y representación geográfica: innovación y aplicación (pp. 463-471). Zaragoza: Universidad de Zaragoza.

Botero, S. (2006). Elementos para leer un palimpsesto: indígenas,caminos, piedras, mulas y caballos en Colombia. Boletín de Antropología Universidad de Antioquia, 20(37), 265-287.

Botero, S. (2007). Redescubriendo los caminos antiguos desde Colombia. Bulletin de l'Institut français d'études andines, 36(3), 343-352.

Cardini, F. (1988). Peregrinos y Viajeros en la Edad Media. Conferencia Inagural de la XVI Semana Internacional de Estudios Medievales. Barcelona. Doi: https://www.raco.cat/index. php/ActaHistorica/article/viewFile/193622/287926

Dalakoglou, D. (2010). The Road. An ethnography of the Albanian-Greek cross-border. American Ethnologist, 37(1), 132-149. DOI: 10.1111/j.1548-1425.2009.01246.x

De La Peña, D. (1997). Adobe, características y sus principales usos en la construcción. México: Instituto Tecnológico de la Construcción.

Gruzinski, S. (1994). Guerra de las imágenes. De Cristobal Colón a Blade Runner (1942-2019). México: Fondo de Cultura Económica.

Guerrero, L.F. (2007). Arquitectura en tierra. Hacia la recuperación de una cultura constructiva. Apuntes, 20(2), 182-201. 
Harvey, P. \& Knox, H. (2015). Roads: An Anthropology of Infrastructure and Expertise. Manchester: Cornell University Press.

Hernández, J. (2011). Los caminos del patrimonio. Rutas turísticas e itinerarios. Pasos. Revista de Turismo y Patrimonio cultural, 9(2), 225-236.

Kalmanovitz, S. (2008). La Economía de la Nueva Granada. Bogotá: Universidad Jorge Tadeo Lozano.

López, F. y Vidargas, F. (2011). Itinerarios Culturales. Planes de Manejo y Turismo Sustentable. México: Instituto Nacional de Antropología e Historia.

Martorell, A. (2003). Los itinerarios culturales como categoría del patrimonio cultural:

su importancia como fuente de proyectos multinacionales de desarrollo. Recuperado de http://www.oei.es/euroamericano/ponencias_patrimonio_itinerarios.php.

Molero, E. (2013). La memoria de los caminos en el Parque Natural Sierras de Cazorla, Segura y las Villas. Patrimonio Intangible e identidad territorial. Revista PH. Bienes, paisajes e itinerarios, (84), 48-85.

Peñuñuri, S. (2016). Antecedentes y Evolución de los Caminos. Recuperado de https://www. academia.edu/RegisterToDownload\#RelatedPapers

Prats, Ll., (1997). Antropología y patrimonio. Barcelona: Grupo Planeta.

Schiiessler, A. (1992). Caminos. Un nuevo enfoque para la gestión y conservación de las redes viales. Santiago de Chile: Comisión Económica para América Latina y el Caribe (CEPAL).

Soro, E. y González, Y. (2015). Patrimonio cultural y turismo: oportunidades y desafíos de la valoración turística del patrimonio. Barcelona: OSTELEA.

Vargas, S. (2013). Tecnologías de la construcción de viviendas y sistema vial. Huaraz Ancash: Universidad Nacional de Ancash. 